\title{
Adenocarcinoma with Metaplasia
}

National Cancer Institute

\section{Source}

National Cancer Institute. Adenocarcinoma with Metaplasia. NCI Thesaurus. Code C4712.

An adenocarcinoma characterized by the presence of metaplasia. 